\title{
Pastoral Care and Mindfulness: A Teaching Practice
}

\author{
Luke Strongman
}

Correspondence: Luke Strongman, Ph. D., Social Sciences, Open Polytechnic of New Zealand, Private Bag 31914, Lower Hutt, 5040, New Zealand.

\author{
Received: January 11, 2017 \\ Accepted: February 7, 2017 \\ Online Published: February 8, 2017 \\ doi:10.11114/jets.v5i3.2210 \\ URL: http://dx.doi.org/10.11114/jets.v5i3.2210
}

\begin{abstract}
From the earliest modern academic literature of industrial organization, supervision education and training, managerial considerations involve leveraging to improve the work of the supervisor and supervisee, and accentuating the value added opportunities for work improvement (Dawson, 1926, pp. 293-295). Reflecting the incorporation of the 'pastoral' within the industrial, Kadushin's model of supervision has short and long-range objectives. The short-range objective is "to improve the [knowledge] worker's capacity to do [his or her] job more effectively". The long-range objective is to instill the capacity to perform a "particular service" that the organization is mandated to offer (Kadushin \& Harkness, 2002, p. 20). This article discusses the concepts of mindfulness and pastoral care in teaching practices. By defining both pastoral care and mindfulness and situating them in a context of relational teaching practice it is argues that self-esteem, confidence and student focused support may be enhanced by the application of concepts from auxiliary health fields.
\end{abstract}

Keywords: supervision, teaching and learning, pastoral care, mindfulness

\section{Introduction}

As Riley (2013) notes, "sustainable pastoral care in education begins with teacher self-care" (p. 112). Holland identifies both the promotion of the 'agency' of the learner and 'trust' as significant goals of teaching practices (Holland 2009, p. 23). Pastoral care and mentoring can provide personal and professional friendship. The educator attempts to transition the novice (who may be inexperienced and academically naive) to scholarly success. Mentoring and pastoral guidance often combines academic guidance with training in associated life skills, which results in academically sustainable behaviours, networking, and self-belief with the goal of autonomous subjectivity in a community of objective dialogue. The mentor collaborates with others to produce research ideas and share advice regarding methodological practices (Mallard 2002, p. 61). Thus, at least temporarily, the mentor-mentoree, or pastoral guidance relationship aims at providing: (i) the 'best quality fit' between education and interests; (ii) balance of career and family; (iii) confidence in abilities; and (iv) scholarly contributions (Mallard 2002, p. 64). An attitude of 'kindness and curiosity' such as that practiced in the 'mindfulness paradigm' is a requisite for pastoral care.

\section{Methodology}

The methodology of this article is qualitative scholarly research from both print-based and online academic sources. A literature survey has been conducted and inductive inferences made about the topic position, to achieve a current state of knowledge finding.

\subsection{What Is Pastoral Care?}

The difference between the student who freezes out' in their answer because they are phased by the lack of recognition they have received on campus, and the one who responds enthusiastically because people acknowledge them and ask 'how they are' is a crucial but overlooked trigger in the consideration of 'pastoral care' in teaching, or considering the student's needs beyond the confines of the subject content and delivery. Pastoral care is about socialising the psychological and self-care health needs of students and clients. The roots of pastoral care are in the overall development of the individual congruent with a 'wellness' approach.

Factors of consideration in pastoral care are manifold. They include (Ravichandran and Mishra, 2014):

- A psychological well-being dimension

- Time-budgeting

- Stress management 
- Goal setting

- Eating a balanced diet

- Exercise - maintenance of scheduled exercise

- Hobbies - putting your mind at ease

In considering the well-being of students 'at the same time' as their instruction, and attention to their learning program, mindfulness can facilitate greater concentration of student needs and increased rapport, responsiveness and empathy. Wright further points out that mentoring enhances other-regarding behaviors. The cues for behavior are grounded in adaptations for survival procreation, which may be mutually co-adaptive $(2009$, p. 105). Amiable and sociable relations matter to productivity and business. Feelings are links in an organization; they are both unifying and trust- and freedom-serving (Wright 2009, p. 108). Good mentoring involves intellectual excitement, positive interpersonal support, rapport, effective motivation, a commitment to learn, friendliness, approachability and respectful understanding (Jones 2008, p. 95).

\subsection{Mindfulness}

Mindfulness is an orientation to experience in which one engages with an attitude of kindness and curiosity. For Siegel, Gormer and Olendski (2009) mindfulness is attention regulated to focus upon immediate experience which leads to greater recognition of mental events in consciousness and the social semiosphere of the 'present moment'. Exponents of the practice of mindfulness argue that human cognition may be hampered by an inability to 'stay focussed in the present' and to dwell on thoughts about past events. The benefits of mindfulness, when it is practiced effectively in both orientation and dialogue in the teaching relationship are manifold and may include: Increased confidence, greater patience, a feeling of being less competitive, and feeling of greater connection, an enhanced sense of humour, a greater connection with humanity, and a greater insight and enhanced sense of security (Nixon, McMurty, Craig, Nevejan, Regan-Addis, 2016, p. 176). Mindfulness may also seem attractive because it has many of the characteristics of a naturalist spirituality within a zeitgeist of personal autonomy and traditional hegemony, currently in vogue in helping industries.

Table 1. Professional benefits of practicing mindfulness (After Nixon et al., 2016, p. 177).

\begin{tabular}{|c|c|c|c|c|c|}
\hline Less reactive & $\begin{array}{l}\text { Recognition of } \\
\text { unconscious process in } \\
\text { self }\end{array}$ & More productive & Greater empathy & Self-care & Reduced stress \\
\hline $\begin{array}{l}\text { Dealing better } \\
\text { with anxiety }\end{array}$ & $\begin{array}{l}\text { Greater } \\
\text { awareness }\end{array}$ & $\begin{array}{l}\text { Greater tolerance of } \\
\text { pain }\end{array}$ & $\begin{array}{l}\text { Enhanced } \\
\text { communication }\end{array}$ & $\begin{array}{l}\text { Mindful use } \\
\text { of power }\end{array}$ & $\begin{array}{l}\text { Mindful } \\
\text { parenting }\end{array}$ \\
\hline $\begin{array}{l}\text { Greater } \\
\text { self-awareness }\end{array}$ & Acceptance of others & Dealing with trauma & Dealing with guilt & $\begin{array}{l}\text { Greater } \\
\text { resilience }\end{array}$ & Confidence \\
\hline $\begin{array}{l}\text { Being more } \\
\text { responsive }\end{array}$ & Greater presence & $\begin{array}{l}\text { Coping with stress / } \\
\text { anxiety }\end{array}$ & Resilience & Well being & Concentration \\
\hline Emotional balance & $\begin{array}{l}\text { Enhanced } \\
\text { relationships }\end{array}$ & $\begin{array}{l}\text { Avoiding destructive } \\
\text { coping strategies }\end{array}$ & $\begin{array}{l}\text { Enhanced emotional } \\
\text { intelligence }\end{array}$ & $\begin{array}{l}\text { Less } \\
\text { rumination }\end{array}$ & $\begin{array}{l}\text { Increased } \\
\text { satisfaction }\end{array}$ \\
\hline Less stress & Effective leadership & $\begin{array}{l}\text { Managing } \\
\text { confrontation }\end{array}$ & Dealing with change & $\begin{array}{l}\text { Increased } \\
\text { well-being }\end{array}$ & Increased focus \\
\hline
\end{tabular}

Mindfulness involves the transformation of neurosis into greater joy, wisdom, compassion insight and possibly personal liberation. It can bring freedom from delusion, enhanced resilience, increased sense of presence and capacity to respond, compassionate leadership, greater balance, and interactions with others may be improved with greater clarity, open creativity, and compassion.

\subsection{Values and Pastoral Care}

As Barrow (2007) has explained, the health paradigm may have an impact on pastoral care through shared values, espoused by health professionals and teachers. The value base of people is tri-partite and informed by three ontological premises. Firstly, that people are 'basically OK' by which is meant that they are of intrinsic value and have right to exist, often expressed in the maxim 'I'm Ok - You're Ok' (p. 21). Secondly, that everyone can think, that people can take in information, they can consider options and make decisions (p. 21). Thirdly, that anyone can change that people have the capacity to grow and learn (p. 21). This, as Barrow explains is a simple idea about maintaining personal recognition as one of the touchstones of how we get recognition from others, practice self-reflection, and make sense of themselves ( $\mathrm{p}$. 21). According to Barrow (2007), four types of 'strokes' or 'other-regarding' behaviour become positive affirmations of social congruency. These are firstly 'positive conditional', and 'negative conditional' involving recognition for what people do, and also 'positive unconditional' and 'negative unconditional' strokes which give recognition to a person ( $\mathrm{p}$. 21) 
Table 2. Transactional Analysis Table

\begin{tabular}{ll}
\hline I'm not OK - You're OK & Tendency to want to seek company of self \\
I'm OK - You're OK & Tendency to want to get along with others \\
I'm not OK - You're Not OK & Tendency is statis / inaction \\
I'm OK - You're Not OK & Tendency to want to dismiss others \\
\hline
\end{tabular}

Desired qualities for negotiation and skill development in the workplace include: Giving direction, taking control, providing safety, giving permission, establishing order, and modelling assertiveness. A second dimension of workplace care is also important involving Taking care of others, offering support and valuing others, nurturing, mentoring and establishing order are a part of structural and inter-personal support. In the teaching context, sometimes there is too much structure and not enough nurture, which gives rise to criticism, humourlessness and over-control. At other times, too much unstructured rapport that tends to reduce overall attentiveness on the task.

However, the exacerbated situation may arise whereby a dyad, triad, or persons are in a relationship of the drama triangle, in which there is a persecutor, rescuer and victim. These relationships are expressed in the attitudes in Figure 1. below.

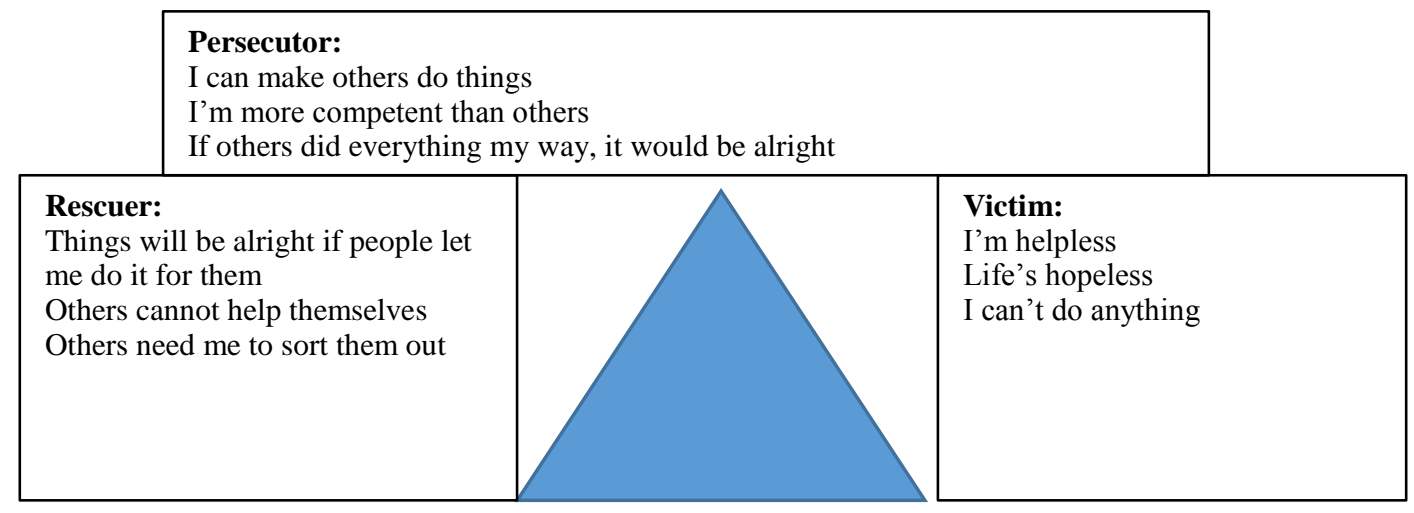

Figure 1. The Drama Triangle (After Karpman, 1968)

There are a variety of possible responses to the drama triangle that involve recognition of the constraints and tensions of the relationship. Secondly, after recognition either persecutor or victim may resolve to reverse behavioural patterns and revise behavioural expectations, ceasing or resisting offensive behaviours. It requires persistence, time and resources to 'climb out of' cycles of helpless and shame. In practicing mindfulness in teaching and exercising openness in pastoral care, it is possible to 'insulate' students from the effects of the drama triangle.

\subsection{Societal Norms and Pastoral Care}

According to Lee (2006), the role of societal norms plays an influence on self-esteem and self-care. Women, for example, who are "socialised to develop feminine characteristics" may have correspondingly vulnerable traits such as lowered self-esteem, lack of a feeling of control, which does not correspond to their true ability and the product of a societal that accentuates masculine traits in their place (p. 340). Therefore, instilling qualities of mindfulness makes it more likely that people will perceive inequities in gender-power relations and prime them to be openly disposed to the talents of others and non-pre-judgemental.

Lee (2006) also points out that there are societal expectations around the maintenance of gender roles. Traditionally masculine identity in males and feminine identity in females, that is consistency between gender and sex-role orientation was a pre-requisite to mental health, if only because in the sense of reproducing wider societal norms and behaviours. Thus as Lee (2006) points out, the internalisation of 'gender-appropriate sex roles' produced people who were considered to be better adjusted (p. 340). Yet the irony remains that whatever the gender, people who are higher in masculine traits will still be more likely to have a better self-concept, self-acceptance, inner-directed support and internal locus of control for a variety of reasons (p. 341). These reasons include, the preponderance of the acceptance of male bias in mainstream social values; the 'loudest voice' is heard most frequently syndrome, and the fact that the more aggressive forms of social messaging - business, advertising, cultural and sorting attainment, still emphasise male characteristics. While men are conditioned to develop 'agency', women are conditioned to develop 'communion' ( $\mathrm{p}$. 342). Correspondingly, development within the western individuated society emphasises behaviours that move from dependence to independence. As Lee (2006) suggested: A "healthy' adult in the individualistic culture is described as an autonomous, competitive, independent achievement and freedom-orientated individual. Accordingly, autonomy, separation, and independence are emphasised as positive characteristics" (p. 348). Yet many studies of social breakdown will emphasise these very characteristics as a triggering attitude. As Calvert (2009) relates the concept of 'care' has at 
least two meanings. The first of which is 'caring for someone' (doing caring work); the second is 'caring about someone' (having caring feelings) (p. 269). In this way the two senses are on a continuum between cold and warm; based on third-party organization or on warmth and friendship; public and private; paid or unpaid (Calvert, 2009, p.270). Hence a theory of educational care needs to encompass both kinds of caring and to recognise that it is not simply and 'augmenting' system for covering-up the deficiencies in the delivery of the curriculum. These activities involved in the social pedagogy of pastoral care have five dimensions (p. 38):

- Care and welfare

- Inclusion

- Socialisation

- Academic support, and

- Social education

As Riley (2013) pointed out, "Sustainable pastoral care in education begins with teacher self-care" (p. 112). Self-reflexivity is important to help the teaching practitioner understand motives to teach. Care for other is predicated in s subset of skills involve in interactions between personality, experiences and values (p. 112). In any transformative enterprise, attachment theory is an approach to interpersonal relationships which may guide relational behaviour and takes into account the set of normal differences in the way people inter-relate. For the most part childhood attachment is uni-directional but in adulthood becomes bi-directional (p. 113). As Thomas (2006) relates, pastoral care has a bearing on the 'therapeutic ethos' (p. 20) which 'responds to interest in the diminished self'. Although it is argued that concepts and language of doing 'therapy' are sometimes appropriated from their original context and hence may lose efficacy, there is an educational rider which justifies their use. As Thomas (2006) states the language of therapeutics has been incorporated into the everyday, for example even the news media reports on the 'national trauma' and he need for 'closure' after natural disasters and criminal acts (p. 21). Although it has been argued that the 'therapeutic ethos' might encourage the 'culture of the victim' 'rather than emphasizing and celebrating peoples' robustness experience shows that therapy is more likely to strengthen than weaken a culture of tolerant values and personal resilience.

\subsection{Pastoral Care and Rules}

Wilson (2002) notes that pastoral care conjures the image of 'sheep-tending shepherds' and that it connotes an attitude of maintenance or supervision that is only peripherally concerned with security or 'blame and punishment' (p. 25). Discipline and punishment is something that in modern societies might only be reserved for behaviour at the margins. In liberal societies the socialisation of behavioural norms is supposed to obviate the need for discipline and punishment, and also the notion of blame for wrong-doing. Most parents who are cognisant of their children educate them with values and attitudes which internalise rules which obviate the need (for the most part) for guilt and blame as a process of regulation from ego id and superego, and are (for the most) part accepting of kinds of authority (p. 25). But Wilson (2002) reminds us that teachers are not policeman. They do not hold (for the most part) disciplinary power over others, rather they exert influence (p. 25). Preferring 'manage' to 'punish' he asserts: "We want first to alert the wrongdoer to his wrongdoing, to make him thoroughly aware both he has done wrong and why he did what was wrong (the way in which he harmed other people, or whatever); to show him what he is being punished for.". This may be the teacher's role, to alert the perpetrator to a wrong doing, make him or her understand it, deter and reform him or her, and to enable him or her to change the character and conditions of life so that they no-longer want to perform any wrong doing. Wilson (2002) notes that in social life and regulation, no single attitude is appropriate. That we are not (for the most part) to judge others but to 'maintain' social life as best we can. Practices of punishment are largely disconnected from those of wrong-doing, collectively agree to enforce certain social norms. As Wilson (2002) relates: “. . . any form of social life or interaction involves norms, rules and expectations; and in default of some special excuse ... the person who breaks the rules is subject to some kind of blame and social disapprobation - perhaps to indignation, or resentment, or even anger on the part of other people, those to whom he has been unjust or whom he has let down" (p. 26). Furthermore, Wilson (2002) establishes a criterion for deriving the aim or goal of punishment. This involves five steps. Does the punishment make the wrong-doer aware of what he has done; does it involve compensating for it? Is the determent sufficient to prevent others from doing it? Does it help to reform his character? involve no permanent damage to self or character / personality and that of others (p. 27). However, in most organizations there is a need to regard people as responsible agents who are subject to praise, blame, reward, punishment and to see them as moral agents or co-participants in social life.

\subsection{Conclusion - Dimensions of Mindfulness in Pastoral Care}

As Kyriacou and Zuin (2016) argue, social pedagogy has a congruence with education as its goal, that is a social element in which individuals would co-exist peacefully and promote a communal well-being, as a form of citizenry and cultural formation (pp. 37-38). A social pedagogy involves relationship established on the ethical dimension of 'trust, care and support', which empowers people to respond to life's challenges. Activities which support this approach 
includes skills in liaison, mentoring, and advising (p. 38). As Smit (2015) pointed out: "The increasing pace of change and the 'dechurchification' of industrialized countries have also accelerated the growth in the helping professions." (p. 2) The growth of the 'helping professions' has stimulated interest in the concept of 'pastoral care' in a wide-variety of industries that are concerned with human development and teaching and learning. According to Kabat-Zinn (2003) mindfulness is the awareness that emerges through paying attention purposefully to present experiences without judgment or preference (p. 167). When used in teaching practice it can help the teacher to focus on the needs of the student, and to co-create an environment of positivity, mutual respect, consideration and caring. Future research could engage in systematic analysis of teaching practices and interventions and re-assess critical junctions for modification of behaviours to include explicit mindfulness behaviours.

\section{References}

Barrow, G. (2007). Transactional Analysis, Pastoral Care and Education. Pastoral Care in Education, 25(21-25). https://doi.org/10.1111/j.1468-0122.2007.00396.x

Calvert, M. (2009). From 'Pastoral Care' to 'Care': Meanings and Practices. Pastoral Care in Education, 27(4), 267-277. https://doi.org/10.1080/02643940903349302

Dawson, J. N. (1926). The casework supervisor in a family agency, Family 6, 293-295.

Holland, C, (2009). 'Workplace Mentoring: a literature review', Ako Aotearoa, accessed 2/4/2010, http://akoaotearoa.ac.nz/download/ng/file/group-4/n3682-workplace-mentoring---a-literature-review.pdf

Jones, A, (2008). Preparing new faculty members for their teaching role, New Directions for Higher Education, 143, 93-100. https://doi.org/10.1002/he.317

Kabat-Zinn, J. (2001). Mindfulness Meditation for Everyday Life. London: Piatkus.

Kadushin, A., \& Harkness, D. (2002). Supervision in Social Work. New York: Columbia University Press.

Karpman, S. (1968). Fairy Tales and Script Drama Analysis. Transactional Analysis Bulletin, 7(26), 39-43.

Kyriacou, C., \& Zuin, A. (2016). Cyberbullying and moral disengagement: an analysis based on a social pedagogy of pastoral care in schools. Pastoral Care in Education, 34(1), 34-41. https://doi.org/10.1080/02643944.2015.1134631

Lee, B. (2006). Caring-self and Woman's Self-esteem: A feminist's Reflection on Pastoral care and Religious Education of Korean-American Women. Pastoral Psychology, 54(4), 337-353. https://doi.org/10.1007/s11089-005-0004-z

Mallard, K (2002). The Soul of Scholarship, New Directions for Teaching and Learning, 90, 59-72.

Nixon, G., McMurtry, D., Craig, L., Nevejan, A., \& Regan-Addis, H. (2016). Studies in mindfulness: widening the field for all involved in pastoral care. Pastoral Care in Education, 34(3), 167-183. https://doi.org/10.1080/02643944.2015.1127990

Ravichandran, N., \& Mishra, R. (2014). Improving efficiency and community-wide practices: benchmarking through integrated pastoral care. International Journal of Healthcare Management, 7(3), 214-220. https://doi.org/10.1179/2047971913Y.0000000068

Riley, P. (2013). Attachment theory, teacher motivation \& pastoral care: a challenge for teachers and academics. Pastoral Care in Education, 31(2), 112-129. https://doi.org/10.1080/02643944.2013.774043

Siegel, R. D. Gormer, C. K., \& Olendski, A. Mindfulness: What Is It? Where Does It Come From? In F. Didonna (Ed.). (2008). Clinical Handbook of Mindfulness. New York: Springer.

Smit, G. H. (2015). Pastoral ministry in a mission age: Towards a practical theological understanding of missional pastoral care, Verbum et Ecclesia, 36(1), 1-8. https://doi.org/10.4102/ve.v36i1.1382

Thomas, D. (2006). Counselling, Culture and Conformity: Some Implications for the Education of Counsellors and Others Involved in Pastoral Care. Pastoral Care in Education, 24(4), 20-25.

https://doi.org/10.1111/j.1468-0122.2006.00386.x

Wilson, J. (2002). Punishment and Pastoral Care. Pastoral Care in Education, 20(1), 25-29. https://doi.org/10.1111/1468-0122.00217

Wright, J. B. (2009). Adam Smith on Instincts, Affection, and Informal Learning: Proximate Mechanisms in Multilevel Selection', Review of Social Economy, 67(1), 95-113. https://doi.org/10.1080/00346760802483679

\section{Copyrights}

Copyright for this article is retained by the author(s), with first publication rights granted to the journal.

This is an open-access article distributed under the terms and conditions of the Creative Commons Attribution license which permits unrestricted use, distribution, and reproduction in any medium, provided the original work is properly cited. 